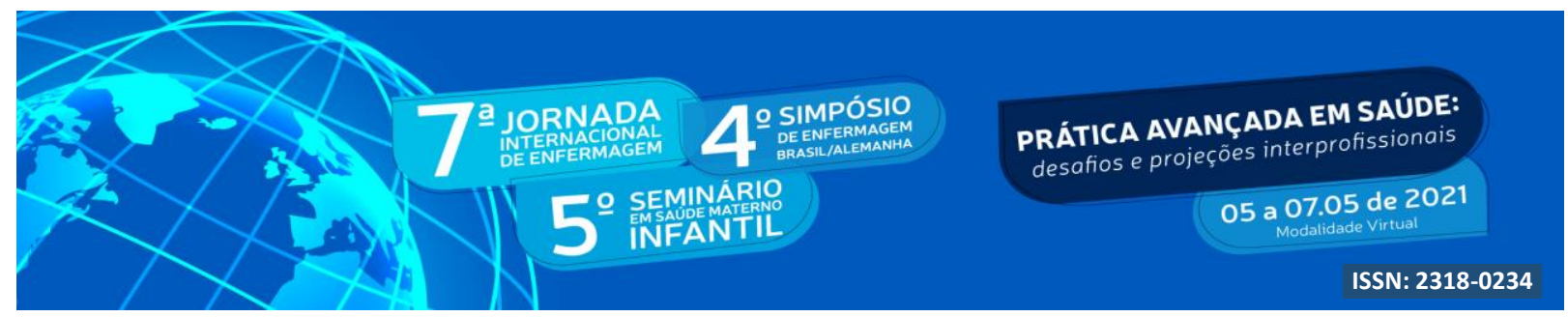

DOI: http://doi.org/10.48195/jie2021-172

\title{
RODAS DE CONVERSA SOBRE AUTOMUTILAÇÃO E ABUSO SEXUAL NA ADOLESCÊNCIA ${ }^{1}$
}

\section{Francisco Fernandes²; Karine de Freitas Cáceres Machado³ Adriana Dall'Asta Pereira $^{4}$; Regina Gema Santini Costenaro ${ }^{5}$}

\begin{abstract}
RESUMO
O presente estudo tem como objetivo relatar a experiência vivenciada por um acadêmico de enfermagem sobre temáticas emergentes abordadas durante as rodas de conversa com um grupo de adolescentes. Utilizou-se a metodologia de pesquisas do cuidado em grupo (MPCG) e analise de conteudo de Bardin para analisar os dados. Durante os momentos dos encontros com os adolescentes observou-se que as tematicas automutilação e abuso sexual estam muito presentes do dia a dia destes jovens. A auto mutilação ocorre quando as pessoas machucam o próprio corpo de formas diversas; o abuso sexual abrange vários tipos de agressões sexuais, como aliciamento e exploração sexual, assédio sexual e estupro. Concluiu-se que e de suma importancia a presença de profissionais capacitados para atuar junto aos adolescentes no que tange estas tematicas elencadas, assim como a necessidade de políticas públicas direcionadas para contemplarem essa demandas.
\end{abstract}

Palavras-chave: Abuso sexual; Adolescência; Automutilação.

\begin{abstract}
The present study aims to report an experience lived by a nursing student on emerging themes addressed during the rounds of conversation with a group of adolescents. Use the group care research methodology (MPCG) and analyze Bardin's content to analyze the data. During the moments of the meetings with the adolescents, it was observed that self-mutilation and sexual abuse are very present in the daily lives of these young people. Self-harm occurs when people injure their bodies in different ways; sexual abuse covers several types of sexual assaults, such as grooming and sexual exploitation, sexual harassment and rape. It was concluded that the presence of professionals trained to work with adolescents regarding these listed themes is of utmost importance, as well as the need for public policies directed to address these demands.
\end{abstract}

Key Words: Sexual abuse; Adolescence; Self-mutilation.

\footnotetext{
${ }^{1}$ Tipo de trabalho e agência financiadora (se não houver agência de fomento, não é necessário acrescentar essa informação).

${ }^{2}$ Acadêmico do Curso de Enfermagem - UFN. 01franciscofernandes@gmail.com

${ }^{3}$ Orientadora Me. Prof. do Curso de Enfermagem - UFN karinecaceresmachado@ gmail.com

${ }^{4}$ Dr$^{\mathrm{a}}$. Prof. do Curso de Enfermagem - UFN adrianadap@terra.com.br

${ }^{5}$ Dra . Prof. do Curso de Enfermagem - UFN reginacostenaro@gmail.com
} 


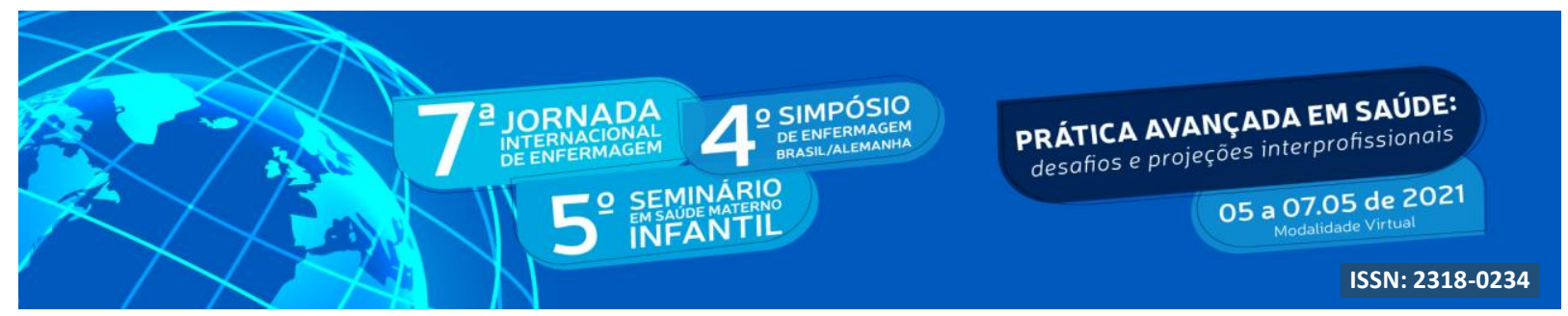

\section{INTRODUÇÃ̃O}

O período que delimita a adolescência, está entre os 10 e os 18 anos de idade segundo a Organização Mundial da Saúde (OMS), reconhecido pelo Ministério da Saúde e pelo Instituto Brasileiro de Geografia e Estatística (IBGE) De acordo com o Estatuto da Criança e do Adolescente (ECA), na lei 8069 de 13/07/1990, é considerada criança até os 12 anos de idade incompletos, sendo compreendido então a adolescência entre os 12 até os 18 anos de idade (BRASIL, 1990).

$\mathrm{O}$ adolescente pela necessidade de encarar suas próprias limitações, para conseguir o desenvolvimento saudável, se envolve em comportamentos de risco e em situações de vulnerabilidade muitas vezes colocando sua própria vida em perigo (SENNA, DESSEN, 2015).

A violência doméstica contra crianças e adolescentes é a que ocorre com maior frequência, sendo capaz de causar danos físicos, sexuais, na área da saúde e/ou psicológicos desses indivíduos (MIORANZA, et al, 2017). Estima-se que no mundo todo, anualmente, cerca de 40 milhões de crianças e adolescentes sofram abuso sexual (SANTOS, et al, 2018).

Quando abordamos a automutilação, estamos nos referindo a pessoas que machucam o próprio corpo de formas diversas, por meio de cortes, queimaduras, auto espancamento, entre outras (ARAUJO, 2016). Em suma, na atualidade, a autolesão em adolescentes é considerada como o resultado final de complexas interações entre fatores genéticos, biológicos, psiquiátricos, psicológicos, sociais e culturais, tornando-se um relevante problema de Saúde Pública (SANTOS, et al, 2018).

\section{OBJETIVO}

Relatar a experiência vivenciada por um acadêmico de enfermagem sobre temáticas emergentes abordadas durante as rodas de conversa com um grupo de adolescentes inseridos em uma escola municipal. 


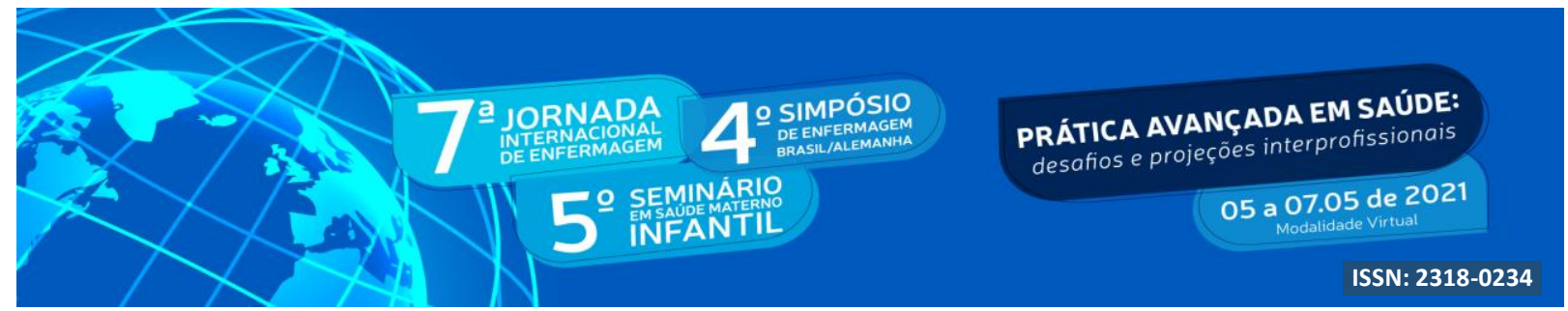

\section{METODOLOGIA}

Este artigo faz parte de um grande projeto intitulado de: Intervenção educativa em saúde envolvendo as temáticas emergentes elencadas por adolescentes. O presente estudo aborda uma pesquisa ação, na mesma utilizou-se a metodologia de pesquisas do cuidado em grupo (MPCG) para a coleta de dados. Esta metodologia surgiu a partir da vivência do cuidado a um grupo de adolescentes que tinham necessidade de dialogar e relatar suas angústias e alegrias, assim como sanar suas dúvidas inerentes à fase da adolescência. Ainda está metodologia de pesquisa disponibiliza ao pesquisador recursos que orientam o cuidado em grupo, permitindo uma escuta sensível e um posicionamento assertivo na condução dos encontros de cuidado e da própria pesquisa. Entende-se por posicionamento assertivo aquele que na definição ou tomada de decisão busca e se apropria da sabedoria para agir ou definir condutas, comportamentos e atitudes. Essa definição envolve atitude proativa, prospectiva e visionária (COSTENARO E LACERDA, 2016).

Etapas da metodologia de pesquisa cuidado em grupo (COSTENARO E LACERDA, 2016): Primeiro momento socializou-se o projeto junto aos membros da escola, que fizeram parte das atividades de pesquisa em grupo. No segundo momento consistiu na preparação do pesquisador para os encontros, ou seja, na medida em que está sendo formado, organizado, divulgado o grupo, o pesquisador subsidiou de conhecimentos sobre as características das pessoas que integrarão o mesmo. No terceiro momento ou $3^{\mathbf{a}}$ Etapa - Avaliação do projeto de pesquisa cuidado em grupo - A cada dois-três encontros, baseado no diário de campo, avaliou-se o andamento do grupo. O pesquisador deve registrar num diário de campo: a temática discutida, o número de participantes de cada encontro, estratégia utilizada para discussão do tema, principais opiniões emitidas, as atitudes/posturas dos participantes frente ao grupo. 


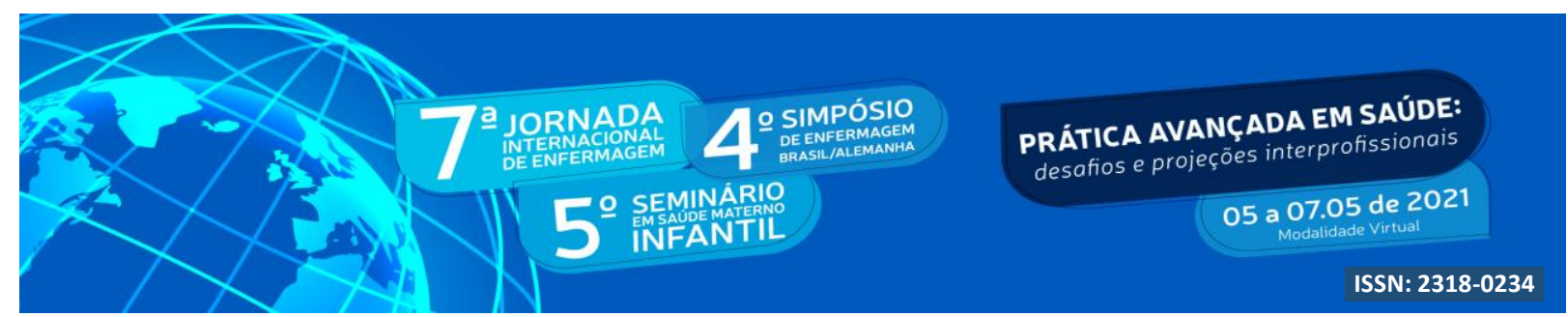

O estudo desenvolveu-se em uma escola, municipal de Santa Maria, Estado do Rio Grande do Sul, totalizando aproximadamente 78 adolescentes que frequentam do $6^{\circ}$ ao $9^{\circ}$ ano do ensino fundamental.

Para participação da pesquisa utilizou-se os seguintes critérios de Inclusão: Pais/responsáveis assinarem o Termo de Consentimento Livre e Esclarecido; -Adolescentes que assinarem o Termo de Assentimento; -Alunos adolescentes com idade entre 13 e 16 anos que estivessem em sala de aula nos dias dos encontros; Critérios de exclusão na amostra: Adolescentes portadores de necessidades especiais. Salienta-se que os adolescentes que não participaram, estavam em atividades paralela com um professor.

A análise dos dados realizou-se conforme a técnica de análise de conteúdo, seguindo as três fases (BARDIN, 2009). Salienta-se que este projeto é parte de um projeto mãe, que já foi aprovado pelo CEP e registrado no CAAE: 01466718.1.0000.5306, e com Número do Parecer: 2.992.469.

\section{RESULTADOS E DISCUSSÃO}

A adolescência implica na complexidade das experiências diversificadas, que variam em função de características individuais e socioculturais, de gênero, classe social, região geográfica, cultura, entre outros (SENNA, DESSEN, 2015).

Participaram como sujeitos da presente pesquisa alunos com idades de 13 a 17 anos. Estes cursavam do $6^{\circ}$ ao $9^{\circ}$ ano do ensino fundamental de uma escola localizada na região central do estado do Rio Grande do Sul.

Muitas vezes os próprios estudantes que não tinham relação com os temas citados traziam para a roda de conversa para fim de, resolver um problema de um ou mais colegas envolvidos na reunião, assim, a ação sendo naturalmente estimulada e agregada por todos envolvidos.

\subsection{AUTOMUTILAÇÃO}




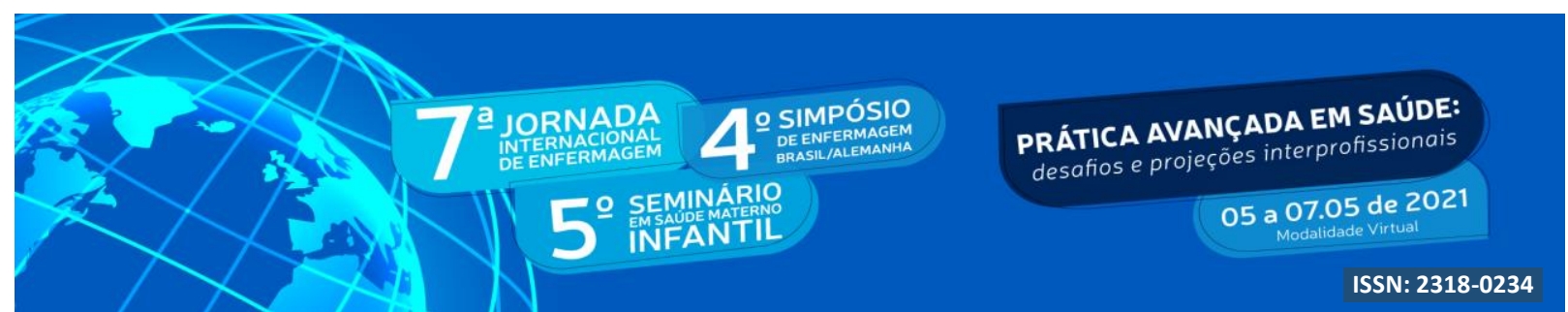

Durante a fase da adolescência, os comportamentos auto lesivos (CAL), são sempre sinal de uma adolescência patológica. Estes comportamentos podem apresentar situações de diferentes gravidades, contudo os CAL, evidenciam um intenso mal-estar, fato que merece muita atenção, e que não deve ser negligenciado (SANTOS, et al, 2020).

Observou-se por meio das rodas de conversa, nos questionários e diário de campo a temática automutilação, presente no cotidiano de vários adolescentes, conforme as falas relatadas abaixo:

"Eu me cortei por que minha familia briga muito $e$ por causa dos problemas que a gente tem vejo que não posso ajudar..." Ágata

"Me corto na barriga para meus pais não verem e para não se preocuparem comigo..." Citrino

"Eu estava muito triste e não sabia como aliviar minha dor..." Pedra da Lua

Quando se aborda sobre automutilação estereotipada, devemos relacionar com atos comportamentais recorrentes, monótonos e fixos, podemos exemplificar como se morder, arranhar-se, bater a cabeça, podendo algumas vezes levar a comprometimento mais graves na saúde do indivíduo (FREITAS e SOUZA, 2017).

Segundo Santos (2020), difcerente da tentativa de suícidio o CAL, demonstra uma dor psíquica, recorrendo a estes atos autolesivos, como forma de lidar com sua dor, isto ocorre de forma privada por forte sentimento de vergonha que causa no indivíduo.

Corroborando Araújo e Carvalho (2008) trazem que os adolescentes recorrem a condutas de risco para que possam redirecionar sua energia e buscar respostas para as suas perguntas e conflitos, e é na escola que esses comportamentos acabam sendo evidenciados ou notados. 


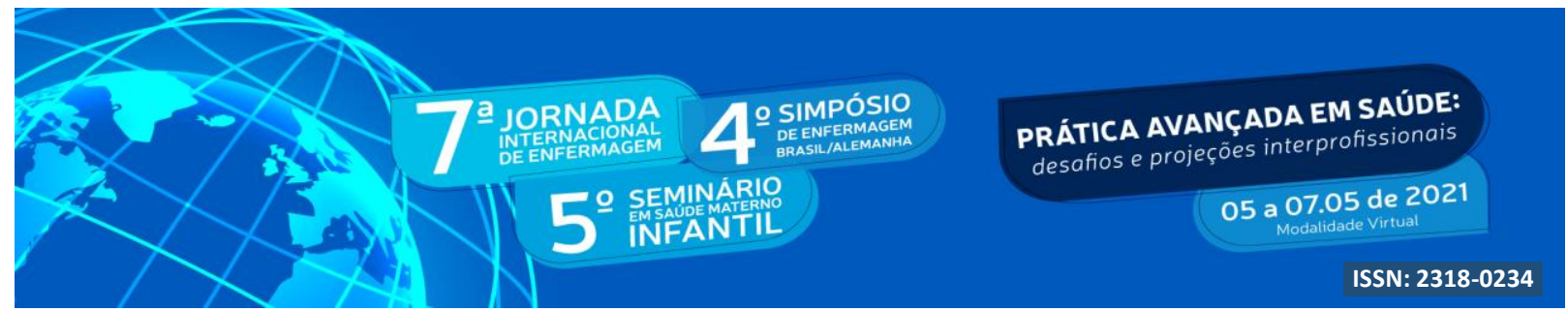

Foi possível perceber durante os encontros na escola que os adolescentes apresentavam lesões no punho e pernas, muitas vezes acometidas por navalhas ou facas. Segundo Reis (2018), no que se refere a patologia boderline associada a transtornos psíquicos, é referente a manifestar fantasias de automutilação, descontrole dos impulsos e agressividade.

A presença de conflitos familiares dentro das próprias casas é um dos maiores motivos de cometer este ato, afim de, chamar a atenção de que o próprio adolescente está sofrendo psicologicamente e assim, fisicamente também. A inserção social não deixa de ser um dos motivos da autolesão, devido a fatores como o próprio bullying, ou devido a autoestima dele.

A importância atribuída à dor corporal nos casos de mutilação remete-nos aos primórdios da psicanálise, à histeria, lugar onde o sofrimento psíquico dirige-se ao corpo (VILHENA e PRADO, 2015).

Segundo Macedo e Fortes (2017), a auto agressividade que estes cortes envolvem circunscreve-se a uma esfera íntima e facilmente acobertada pelo adolescente, ou seja, a vida privada ou social deste indivíduo afeta diretamente sua saúde mental, ocasionando a autolesão. Sendo comum na adolescência, cabendo aos profissionais acompanhar e identificar quais fatores estão influenciando a vida do mesmo, evitando talvez, um possível potencial de suicídio.

A atitude de cometer a automutilação pelos adolescentes foi evidenciada pela fraqueza da relação familiar, social e econômica destes, para fim de, aliviar sua dor emocional/psíquica de alguma forma. Os meninos eram mais difíceis de identificar devido ao local das lesões, como no abdômen e coxas. Já a menina era facilmente de identificar por ser comumente no braço e punho, sendo lesões acometidas por navalhas, ou até mordidas. Adolescentes com problemas de saúde mental ou uso de substâncias, sem escolaridade, formação profissional e/ou emprego são grupo de alto risco para automutilação (SILVA e BOTTI, 2017).

Os adolescentes e seus familiares devem buscar o tratamento psicológico quando passam por estes tipos de situação, fazendo com que o adolescente tenha um amparo profissional e adequado para evitar possíveis reincidência de tal fato, assim como em muitos casos os ferimentos são profundos e necessitam de acompanhamento de profissional 


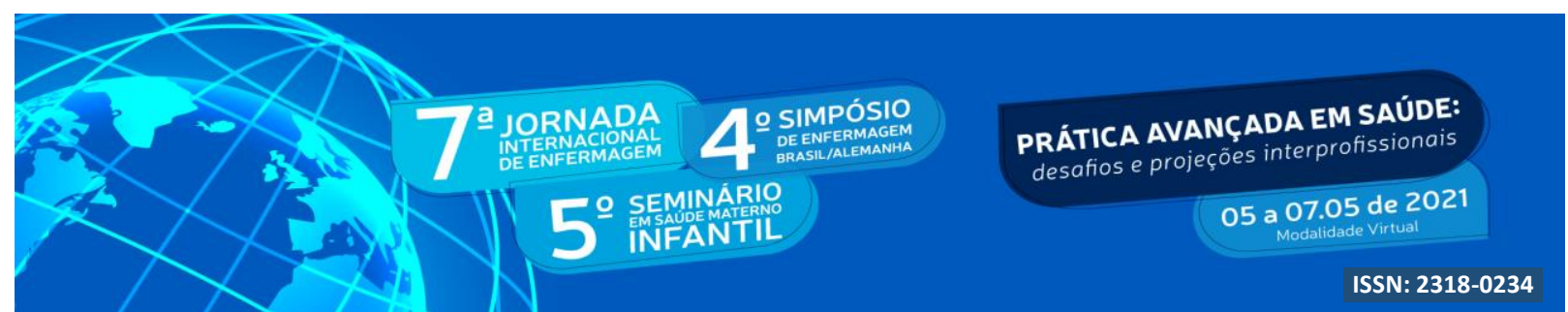

capacitado para realizar a avaliação destes e realizar os curativos desta ou destas lesões, a fim de evitar complicações.

\subsection{ABUSO SEXUAL}

No que tange a temática Abuso Sexual, nas rodas de conversa ficou muito claro que um número muito expressivo dos participantes já havia sofrido algum tipo de abuso sexual. Este crime é dificilmente encontrado e notificado, devido muitas vezes, do abusador ser membro da família da vítima e o restante acobertar o mesmo como podemos observar nos relatos:

"O namorado da minha mãe, quando ela vai trabalhar, ele vai no meu quarto e fica me tocando..." Âmbar

"O meu irmão mais velho fica querendo fazer coisas comigo, mas eu não consigo sair por que ele é mais forte que eu, já falei para minha mãe, mas ela não acredita..." Rubi

"Eu tento desviar do meu padrasto, mas ele sempre acaba me dando uns abraços estranhos..." Diamante

Sabe-se que para a criança, parece ser mais difícil definir assédio, atentado ao pudor, pornografia infantil e demais tipos de violência, o que dificulta a denúncia e/ou explicação dos fatos (SANTOS et al, 2018).

Segundo dados do Sistema de Informação de Agravos de Notificação (Sinan), a violência sexual ocupa a segunda posição entre as agressões contra adolescentes na faixa etária de 10 a 19 anos, com 23,9\% das notificações, sendo ultrapassada apenas pela violência 


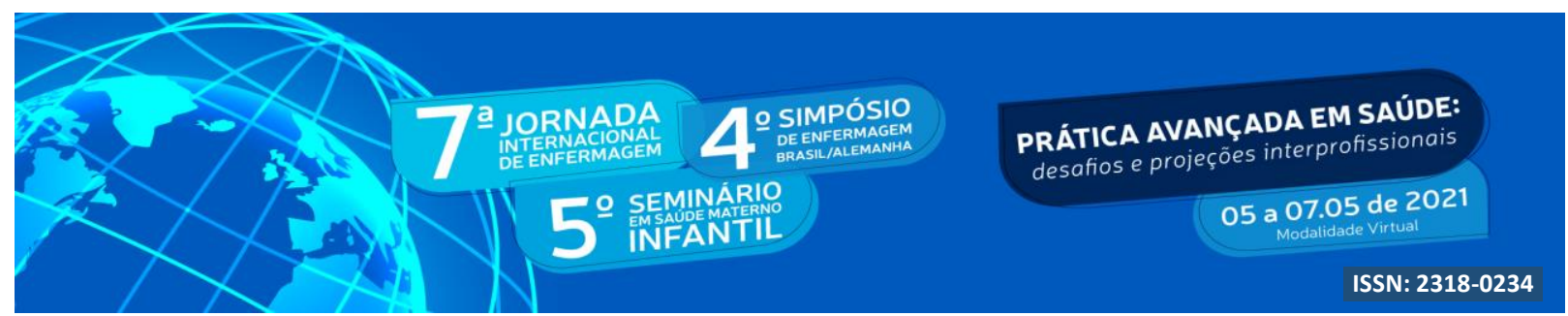

física, com 63,3\% (IBGE, 2016). A Pesquisa Nacional de Saúde do Escolar (PeNSE), realizada em 2015 revelaram: 4,0\% dos escolares entrevistados afirmaram terem sido forçados a ter relação sexual, variando de $4,5 \%$ das meninas e $3,7 \%$ dos meninos (IBGE, 2016)

Os adolescentes abusados têm elevado risco de desenvolver uma série de transtornos biopsicossociais, com repercussões sobre as esferas física, comportamental e cognitiva (MACHADO, CONCEIÇÃO, FONTES, 2017). Notou-se durante as reuniões com os adolescentes a presença de diversas pessoas que mudaram suas emoções devido a importância do assunto em suas vidas.

A grande quantidade de meninas que sofrem abuso sexual por parte de amigos de seus pais, namorados ou padrastos de suas mães ou até vizinhos é uma preocupação que deve ser dialogada com os alunos para fim de dar um basta neste tipo de situação que muitas pessoas tentam enfrentar em suas casas. Um dos problemas maiores é a mãe não acreditar em sua filha quando a mesma relata estar sofrendo abuso sexual, lembrando que, carinhos interpretados pelos jovens como desconfortáveis, não deixam de ser um abuso.

Traumas como estes são extremamente perigosos para um desenvolvimento saudável para o jovem, devido a fatores que levam o mesmo a ter medo de se envolver com alguém futuramente, insegurança, e falta de confiança pela família.

\section{CONCLUSÃO}

Concluiu-se a necessidade da inserção de psicólogos dentro das escolas para fim de ter um momento destinado a saúde mental dos adolescentes, para assim então, diminuir os índices de automutilação, e o aumento de denúncias relacionadas a violência sexual infantil.

A importância de naturalizar diálogos relacionados com estes temas é necessária para a construção de uma ideologia em que o ser humano com sua singularidade tens que desmistificar assuntos que não devem ser guardados para si próprio. Assim, a família como responsável dos menores de idade também assumirem o papel de cuidador e adquirir uma escuta qualificada, e não infantilizar o que o jovem está passando no momento. 


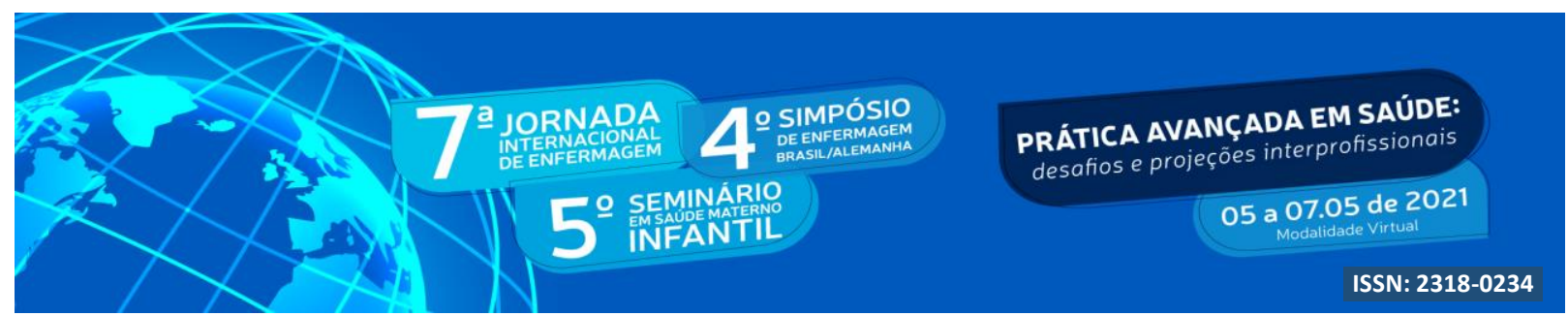

A necessidade de políticas públicas que estimulem as escolas a realizar reuniões de apoio para o diálogo com enfoque de suas angústias, problemas pessoais em que o jovem passa, para fim de melhorar a qualidade de vida de todos envolvidos.

\section{REFERENCIAS}

ARAUJO, J. F. B. et al. O CORPO NA DOR: AUTOMUTILAÇÃO, MASOQUISMO E PULSÃO. Estilos clin., São Paulo, v. 21, n. 2, maio/ago. 2016, 497-515.

ARAÚJO, L.F; CARVALHO, D. Adolescência, escola e prevenção: dinâmicas sobre a sexualidade e as drogas. 3a ed. Rio de Janeiro: Wak; 2008.

BARDIN, L. Análise de Conteúdo. Tradução de Luís A. Reto e Augusto Pinheiro. 5 ed. Lisboa: Edições 70, 2009.

BRASIL. Presidência da República. (1990). Estatuto da Criança e do Adolescente. Lei 8069, de 13 de julho de 1990. Disponível em: < http://www.planalto.gov.br/ccivil_03/leis/18069.htm>.

COSTENARO, R. G. S.; LACERDA, M. R.; Metodologias da pesquisa para a Enfermagem e Saúde: da teoria à prática. Porto Alegre, PA: Editora Moriá, 2016.

FREITAS, E. Q. M; SOUZA, R. Automutilação Na Adolescência: Prevenção E Intervenção Em Psicologia Escolar. Revista Ciência (In) Cena. On-line ISSN 2317-0816 Vol. 1 No. 5 Salvador. Bahia. 2017. Disponível em: <http://periodicos.estacio.br/index.php/cienciaincenabahia/article/view/4356/pdf4356>

IBGE. Instituto Brasileiro de Geografia e Estatística. Pesquisa Nacional de Saúde do Escolar, 2015 [Internet]. Rio de Janeiro: IBGE; 2016132 p. Disponível em: https://biblioteca.ibge.gov.br/visualizacao/livros/liv97870.pdf.

Instituto Brasileiro de Geografia e Estatística. Pesquisa Nacional de Saúde do Escolar, 2015. Rio de Janeiro: IBGE; 2016. 132 p. Disponível em: Disponível em: https://biblioteca.ibge.gov.br/visualizacao/livros/liv97870.pdf

MACEDO, M. M. K. FORTES, I. Automutilação na adolescência - rasuras na experiência de alteridade. Psicogente, 20(38), 353-367, 2017.

MACHADO, S; CONCEIÇÃO, O. C; FONTES, L. F. C. Violência sexual na adolescência, perfil da vítima e impactos sobre a saúde mental. Ciênc. Saúde coletiva vol.22 no.9 Rio de 


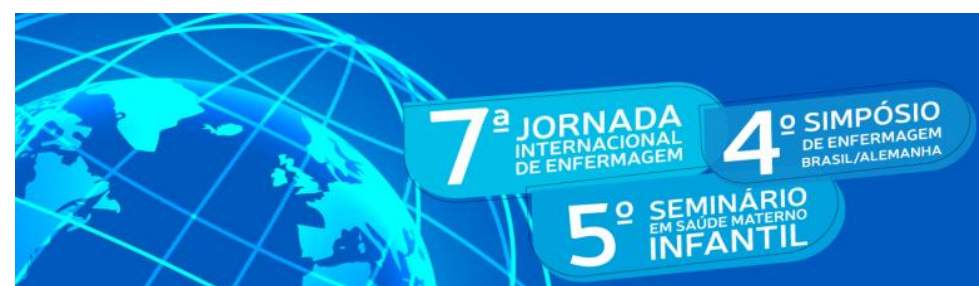

PRÁTICA AVANÇADA EM SAÚDE:

desafios e projeções interprofissi

05 a 07.05 de 2021

ISSN: 2318-0234

Janeiro

Sept.

2017.

Disponível

em:

<https://www.scielo.br/scielo.php?script=sci_arttext\&pid=S141381232017002902919>

MIORANZA, A; ROCHA, R; BOLSON, S. B. ABUSO SEXUAL INFANTIL-JUVENIL: INTERFACES COM A SAÚDE. Revista Humano Ser - UNIFACEX, Natal-RN, v.3, n.1, p. 47-65, 2017/2018.

REIS, M. N. Automutilação: o encontro entre o real do sofrimento e o sofrimento real. Polêm!ca, v. 18, n. 1, p. 50-67, janeiro, fevereiro e março 2018 - DOI: 10.12957/polemica.2018.

SANTOS, M. J; et al. Caracterização da violência sexual contra crianças e adolescentes na escola - Brasil, 2010-2014. Epidemiol. Serv. Saude, Brasília, 27(2):e2017059, 2018.

SANTOS, A. A; et al. AUTOMUTILAÇÃO NA ADOLESCÊNCIA: COMPREENDENDO SUAS CAUSAS E CONSEQUÊNCIAS. Temas em Saúde, volume 18, número 3, 2018.

SANTOS, J.H.R. M; PIRES, C. F; PEREIRA, D.M; SILVA, D.L. Comportamento autolesivo em adolescentes de escola pública. Adolesc. Saude, Rio de Janeiro, v. 17, n. 2, p. 34-41, abr/jun 2020.

SENNA, S. R. C. M, DESSEN, M. A. Reflexões sobre a saúde do adolescente brasileiro. PSICOLOGIA, SAÚDE \& DOENÇAS. v.16, n.2, p:217-229, 2015. Disponível em: http://www.scielo.mec.pt/pdf/psd/v16n2/v16n2a08.pdf

SILVA, A. C; BOTTI, N. C. L. Comportamento Autolesivo Ao Longo Do Ciclo Vital: Revisão Integrativa Da Literatura. Revista Portuguesa de Enfermagem de Saúde Mental, V. 18, P. 72, 2017. Disponível em: 〈http://www.scielo.mec.pt/pdf/psd/v16n2/v16n2a08.pdf>

VILHENA, M; PRADO, Y. Z. C. Dor, angústia e automutilação em jovens - considerações psicanalíticas. Adolesc. Saude, Rio de Janeiro, v. 12, n. 2, p. 94-98, abr/jun 2015. Disponível em: https://cdn.publisher.gn1.link/adolescenciaesaude.com/pdf/v12n2a12.pdf 